\title{
BASAL SLIDING RELATIONS DEDUCED FROM ICE-SHEET DATA
}

\author{
By L. W. Morland, G. D. Smith, \\ (School of Mathematics and Physics, University of East Anglia, Norwich NR4 7TJ, England) \\ and $\mathrm{G}$. S. Boulton \\ (School of Environmental Sciences, University of East Anglia, Norwich NR4 7TJ, England)
}

\begin{abstract}
The sliding law is defined as a basal boundary condition for the large-scale bulk ice flow, relating the tangential traction $\tau_{\mathrm{b}}$, overburden pressure $p_{\mathrm{b}}$, and tangential velocity $u_{\mathrm{b}}$ on a smoothed-out mean bed contour. This effective bed is a lower boundary viewed on the scale of the bulk ice flow and is not the physical ice/rock or sediment interface. The sliding relation reflects on the same scale the complex motion taking place in the neighbourhood of the physical interface. The isothermal steady-state icesheet analysis of Morland and Johnson $(1980,1982)$ is applied to known surface profiles from the Greenland ice sheet and Devon Island ice cap, with their corresponding mass-balance distributions, to determine $\tau_{\mathrm{b}}, p_{\mathrm{b}}$, and $u_{\mathrm{b}}$ for each case. These basal estimates are used in turn to construct, using least-squares correlation, polynomial representations for an overburden dependence $\lambda\left(p_{\mathrm{b}}\right)$ in the adopted form of sliding law $\tau_{\mathrm{b}}=\lambda\left(p_{\mathrm{b}}\right) u_{\mathrm{b}}{ }^{1 / m}$ with $m \geqslant 1$.

The two different data sets determine functions $\lambda\left(p_{\mathrm{b}}\right)$ of very differen magnitudes, reflecting very different basal conditions. $A$ universal sliding law must therefore contain more general dependence on basal conditions, but the two relations determined appear to describe the two extremes. Hence use of both relations in turn to determine profiles compatible with given mass-balance distributions can be expected to yield extremes of the possible profiles, and further to show the sensitivity of profile form to variation of the sliding relation. The theory is designed as a basis for reconstruction of former ice sheets and their dynamics which are related to the two fundamental determinants of surface mass balance and basal boundary condition.
\end{abstract}

Résumé. Lois de glissement au fond déduites de donnèes d’expériences sur les calotles glaciaires. La loi de glissement est définie comme une condition aux condition aux limites de base pour l'écoulement des masses glaciaires à grande échelle, liant la force tractrice tangentielle $\tau_{\mathrm{b}}$, la pression au fond $p_{\mathrm{b}} \mathrm{et}$ la vitesse tangentielle $u_{\mathrm{b}}$ sur un tracé moyen "lissé" du lit. Ce lit effectif est la limite inférieure de la glace vue à l'échelle de l'écoulement en masse mais n'est pas l'interface physique entre glace et rocher ou moraine. La relation de glissement reflète à la mème échelle le mouvement complexe dont est le siège la zone voisine de l'interface physique. L'analyse de l'état d'équilibre isotherme d'une masse glaciaire proposée par Morland et Johnson (1980, 1982) est appliquée à des profils de surface connus au Groenland et à la calotte glaciaire de l'ile Devon, avec les distributions correspondantes des bilans de masse pour déterminer $\tau_{\mathrm{b}}, p_{\mathrm{b}}$ et $u_{\mathrm{b}}$ dans chaque cas. On utilise en retour ces estimations sur ce fond pour construire, par corrélation aux moindres carrés, des représentations polynomiales pour une fonction de la profondeur $\lambda\left(p_{\mathbf{b}}\right)$ dans la forme adoptée pour la loi de glissement $\tau_{\mathrm{b}}=\lambda\left(p_{\mathrm{b}}\right) u_{\mathrm{b}}{ }^{1 / m}$ avec $m \geqslant 1$.

Les deux ensembles de données fournissent des fonctions $\lambda\left(p_{\mathrm{b}}\right)$ d'ordres de

\section{INTRODUCTION}

Direct observations suggest that glaciers whose soles are at the melting point slide directly over their beds (e.g. Kamb and LaChapelle, 1964; Peterson, 1970; Boulton and others, 1979; Vivian, 1980), or that an equivalent subglacial motion takes place within an underlying layer of deforming sediment (Boulton, 1979). observations also suggest that in cold-based glaciers there is no such subglacial decollement, but that the glacier sole adheres to its bed (Goldthwait, 1960; Holdsworth, 1974[b]). However, in this case an "apparent bed" may occur as a well-defined shear plane within the ice immediately above a basal boundary layer of ice (Holdsworth, 1974[b]; Boulton, 1972).

It is supposed that sliding or décollement beneath temperate ice occurs because of the presence of a $\mathrm{film}$ of water between it and a bedrock surface, or because of high pore-water pressures in unlithified sediments grandeur très différents reflétant des conditions au fond très différentes. Une loi universelle de glissement doit donc faire intervenir de manière plus générale les conditions au fond mais les deux relations trouvées semblent décrire les deux cas extrêmes. Dès lors, l'utilisation des deux relations tour à tour pour déterminer les profils compatibles avec une distribution donnée des bilans de masse, peut, espère-t-on, donner les limites extrèmes des profils possibles et donc montrer la sensibilité de la forme du profil à la variation de la loi de glissement. La théorie est proposée comme une base pour la reconstitution des anciennes calottes glaciaires et de leur dynamique qui sont déterminées fondamentalement par les deux caractéristiques que sont les bilans de masse en surface et l'état du lit au fond.

Zusammenfassung. Beziehungen für das Gleiten am Untergrund, hergeleitet au. Eisschilddaten. Das Gleitgesetz wird als Randbedingung am Untergrund für den grossmassstäbigen Fluss einer Eismasse definiert; es setzt die tangentiale Zugspannung $\tau_{\mathrm{b}}$, den Auflagedruck $p_{\mathrm{b}}$ und die Tangentialgeschwindigkeit $u_{\mathrm{b}}$ auf einer geglätteten Hohenlinie des mittleren Bettes miteinander in Bezeihung. Dieses wirksame Bett ist eine untere Begrenzung bezüglich des Masseneisflusses und fallt nicht mit der physikalischen Grenzfläche zwischen Eis und Fels oder Sediment zusammen. Die Gleitbeziehung beschreibt im selben Massstab die komplexe Bewegung, die in der Umgebung der physikalischen Grenzfläche stattfindet. Die Analyse eines isothermen, stationären Eisschildes von Morland und Johnson (1980, 1982) wird auf bekannte Oberflächenprofile des grönländischen Eisschildes und der Devon Island-Eiskappe angewand, um mit den zugehörigen Verteilungen der Massenbilanz die Grössen $\tau_{\mathrm{b}}, p_{\mathrm{b}}$ und $u_{\mathrm{b}}$ für jeden Fall zu bestimmen. Die Abschätzungen für den Untergrund werden ihrerseits unter Anwendung der Methode der kleinsten Quadrate zur Konstruktion einer polynomialen Darstellung für eine Auflastbezeiehung $\lambda\left(p_{\mathrm{b}}\right)$ in der angenommenen Form des Gleitgesetzes $\tau_{\mathrm{b}}=\lambda\left(p_{\mathrm{b}}\right) u_{\mathrm{b}}{ }^{1 / m}$ mit $m \geqslant 1$ herangezogen.

Die beiden verschiedenen Datensätze ergeben Funktionen $\lambda\left(p_{\mathrm{b}}\right)$ von sehr verschiedener Grössenordnung, entsprechend den sehr verschiedenen Verhältnissen am Untergrund. Ein universelles Gleitgesetz muss daher allgemeinere Abhängigkeit von den Untergrundsverhältnissen enthalten, doch scheinen die beiden ermittelten Beziehungen die beiden Extreme zu beschreiben. Daher kann erwartet werden, dass der Gebrauch der beiden Beziehungen zur Bestimmung von Profilen, die gegebenen Verteilungen der Massenbilanz entsprechen, die Extreme der möglichen Profile liefert; weiterhin dürfte er die Abhängigkeit der Profilform von Änderungen der Gleitbeziehung zeigen. Die Theorie soll als Basis zur Rekonstruktion früherer Eisschilde und ihrer Dynamik auf der Grundlage der beiden fundamentalen Einflussparameter Massenbilanz an der Oberfläche und Randbedingung am Untergrund dienen.

which reduce their frictional resistance and allow them to deform. As yet, theories of basal ice movement have largely been developed from Weertman's (1957, 1964) model of temperate ice sliding over a bedrock surface (recently reviewed by Weertman, 1979; see also Lliboutry, 1979).

The sliding law is a basal boundary condition for the large-scale bulk ice flow, and relates the tangential traction $\tau$ b on a (smoothed-out) bed contour to the tangential velocity $u_{b}$ of the ice at this boundary in the same direction. Strictly $\tau_{b}$ and $u_{b}$ should be vectors in a tangent plane to allow a component of traction normal to the local sliding direction, but three-dimensional sliding theories tacitly assume that $\tau_{b}$ and $u_{b}$ are parallel. Negligible sliding velocity at this apparent bed, reflecting non-slip at the neighbouring real bed, must be a possible result.

The classical sliding theory introduced and extended by Weertman $(1957,1964)$ considers a bed consist- 
ing of a regular array of cuboidal objects with a bed roughness parameter defined by their size and spacing. Weertman derives a sliding velocity from the two components of regelation slip and plastic flow past the obstacles for a given basal shear stress. The resulting law has the form

$$
u_{b}=B \tau_{b}(n+1) / 2
$$

where $n$ is the exponent in the creep law deduced by Glen (1955) from uniaxial compression tests. Lliboutry (1968) deduced a similar law but with disagreement over the appropriate measure of bed roughness and the magnitude of $B$. The form of the sliding law in Equation (1), with $n=1$, has been supported by Nye (1969) and Morland (1976) for the Newtonian-fluid approximation, but the significant non-linear viscous response of ice defies similar treatment. The simplifications inherent in these formulations have, however, made it difficult to test the law in the field.

Fowler $(1979,1981)$, in his analysis of sliding, defines two roughness parameters: the bed asperity $\sigma$, defined as the bed roughness wavelength $[x]$ relative to ice depth d, and the bedrock roughness slope $v$ defined as roughness amplitude [y] relative to wavelength $[\mathrm{x}]$. He assumes a steady plane flow comprising an outer flow over the smoothed bed contour and an inner flow in a boundary layer on the scale of the roughness wavelength with perfect slip on the actual bed contour. The sliding velocity $u_{b}$ is both the velocity of the outer flow evaluated on the smoothed bed contour, and also the far-field velocity for the boundary-layer flow. Assuming a periodic bed contour and that ice satisfies Glen's creep law, a singular perturbation analysis for $\sigma \ll 1$, with the further restriction $v^{n+1} \ll 1$, gives a lead-order relation

$$
u_{b}=\sigma v^{-(n+1)}\left(\tau_{b} / R\right)^{n},
$$

where $R$ is an order-unity roughness parameter independent of $\sigma$. In Equation (2), both $u_{b}$ and $\tau_{b}$ are dimensionless variables, with respective units a longitudinal velocity magnitude and deviatoric stress magnitude in the outer flow. Note the power $n$ in Equation (2) in contrast to $\frac{1}{2}(n+1)$ of Equation (1), and further that the Newtonian assumption $(n=1)$ of Nye (1969) and Morland (1976) cannot differentiate between either form.

$$
\text { Equation (2) can also be written }
$$

$$
\tau_{b}=k\left(d u_{b}\right)^{1 / n}
$$

where $d$ is the ice thickness, although Fowler's analysis applies only to $d \gg x[x]$, the bed roughness wavelength, so does not allow the limit $d \rightarrow 0$. A simple extension of Equation (3) to allow variation of the thickness from its maximum magnitude in the central zone to zero at the margin is a separable relation

$$
\tau_{b}=\lambda(d) \beta\left(u_{b}\right) \text { or } \tau_{b}=\lambda(d) u_{b} 1 / m
$$

where the "friction parameter" $\lambda$ depends on overburden depth d, or equivalently on the overburden pressure $\mathrm{p}_{\mathrm{b}}$, and on the bed form and properties. The explicit function $\beta$ in the second of Equations (4) with arbitrary exponent $m$ is consistent with both Equations (1) and (3). Here we assert that the minimal ingredients of a sliding relation on the smoothed bed contour must be the tangential traction $\tau$, the tangential velocity $u_{b}$, and the overburden pressure $\mathrm{p}_{\mathrm{b}}$. Ignoring dependence on $\mathrm{p}_{\mathrm{b}}$, as in Equation (1) for example, leads to singular behaviour at a margin. The second of Equations (4) with different $m$ and with creep described by a power law of exponent $n$ (Glen, 1955 ), or a polynomial law (Colbeck and Evans, 1973), has been applied by Morland and Johnson $(1980,1982)$, hereafter abbreviated to MJ, and by Johnson (1981) to determine small-slope, steady ice-sheet profiles. A polynomial law has a finite non-zero gradient, that is bounded viscosity, as stress approaches zero, in contrast to the infinite viscosity of a power law with $n>1$. In the following conclusions $n=1$ refers to any smooth creep law with bounded viscosity. It was shown that bounded flows at the margins and ice divide, where the shear stress approaches zero, require

$$
\begin{aligned}
\lambda \simeq & d \text { as } d+0, \min (n, m)=1, \\
m= & 1,2, \text { or } 23 \text { if } n=1, \\
& \text { and } n=1,2, \text { or } \geqslant 3 \text { if } m=1 .
\end{aligned}
$$

It was further noted (Morland and Johnson, 1982) that bounded longitudinal stress at the free surface requires $n=1$. The optimum choice $n=m=1$ corresponds to a bounded-viscosity creep law, such as a polynomial, and a sliding relation of the form of the second of Equations (4) which is linear in ub as $u_{b} \rightarrow 0$. The margin requirement that $\lambda$ is linear in $\mathrm{d}$ as $\mathrm{d} \rightarrow 0$ is equivalent to linearity in $\mathrm{pb}$, and supports the assertion that a sliding relation must depend on $\mathrm{Pb}$. In addition, the sliding relation is expected to depend on temperature, at least to distinguish temperate and cold basal conditions, but the present analysis does not account for temperature variation.

Our analysis comprises an inversion of the MJ steady, isothermal, plane-flow solution to determine $u_{b}, \tau_{b}$, and $p_{b}$ from given profile, bed, and surface accumulation/ablation area. Data from an individual ice sheet determine their distributions along the span and, subject to appropriate monotonicity properties, will determine one function of one variable in a connecting relation. Thus, even a separable twofunction relation such as the first of Equations (4) cannot be determined, so an empirical sliding model must be restricted to a single-function form. We therefore adopt a relation of the form

$$
\tau_{b}=\lambda\left(p_{b}\right) u_{b} 1 / m
$$

with one arbitrary function $\lambda\left(p_{b}\right)$ to determine from individual ice-sheet data for different values of an integer exponent $\mathrm{m}$. The correlation is carried out for two very different ice masses. First, the Expedition Glaciologique Internationale au Groenland (EGIG) profile of the present Greenland ice sheet (Holtzscherer and Bauer, [1956]; Hofmann, 1974). Secondly, the northwest profile of the Devon Island ice cap (Hyndman, 1965; Müller, 1977, p. 147-54), which is an order of magnitude smaller than the Greenland ice sheet. As expected, the magnitudes of the respective coefficients $\lambda\left(p_{b}\right)$ are very different, reflecting very different basal conditions. We suggest, though, that these two examples represent fairly extreme conditions, so that profile reconstructions using both relations would determine appropriate outer bounds. Naturally, the choice of $m$ influences the pressure dependence of $\lambda$. We also find that there is no sensible $B\left(u_{b}\right)$ in the alternative single-function relation

$$
\tau_{b}=p_{b} B\left(u_{b}\right)
$$

which is consistent with the Greenland data. It is understood that our data correlation does not confirm a sliding relation of the form of Equation (6), but simply determines a basal boundary condition for the smoothed boundary of the global flow, which reconstructs the known profile from the given accumulation data.

It is known that significant temperature variation occurs in cold ice sheets, and that ice creep is significantly temperature-dependent in the relatively warm zones. The isothermal approximation allows only the specification of a constant temperature in the rate factor, and we recognize that a proper thermomechanical analysis could yield a different distribution of basal velocity, and hence correlate with different coefficients $\lambda\left(p_{b}\right)$. In particular, the calculated basal sliding velocity ub on the smoothed bed may well be reduced if enhanced velocity gradients in 
warmer zones increase the differential velocity between the surface and bed. Alternatively, if the enhancement occurs mainly in a thin thermal boundary layer below the adopted smooth bed, as proposed in Nye's (1959) pioneering ice-sheet analysis, then the basal sliding velocity so defined would be increased. We offer the present empirical models as the first quantitative correlation of a mechanical relation of the form of Equation (6) with global ice-sheet data, to be used for theoretical ice-sheet reconstructions until a sound thermomechanical theory is available.

\section{STEADY ISOTHERMAL PLANE-FLOW THEORY}

Plane flow with velocity components $(u, v)$ in 0xy (Fig. 1) is assumed, where $x, y$ are rectangular Cartesian axes with $0 x$ horizontal. The bed contour

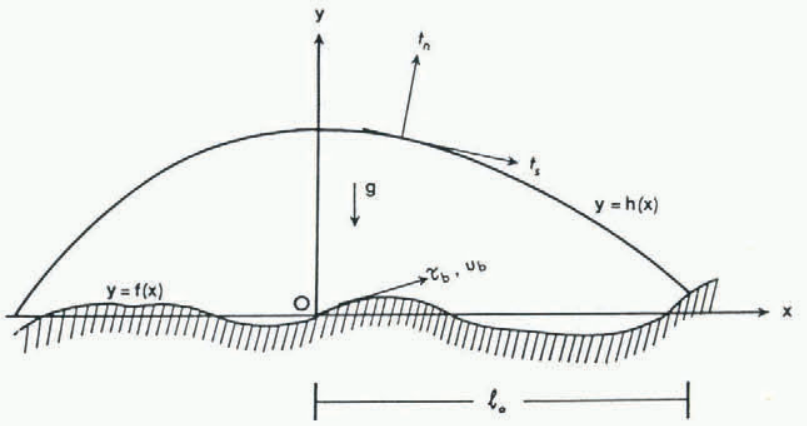

Fig. 1. Ice-sheet cross-section.

$y=f(x)$ is restricted to small slope $f^{\prime}(x)$, and small mean bed inclination to the horizontal can be incorporated in the function $f(x)$. The ice sheet has a free surface $y=h(x)$, on which the normal and tangential tractions $t_{n}$ and $t_{s}$ are zero, and on which there is an accumulation distribution $q$ defined as the volume flux of ice per unit horizontal cross-section entering the sheet. Negative $q$ denotes ablation. Basal drainage $b$ on $y=f(x)$ is the volume flux of ice leaving the sheet per unit horizontal crosssection. Let $q_{m}$ denote a maximum accumulation ( $a b l a-$ tion) magnitude, and let $h_{0}$ be a sheet thickness magnitude and $\ell_{0}$ a semi-span magnitude.

We assume that the ice behaves like an incompressible non-linearly viscous fluid on gravity-drivenflow time scales, and satisfies a constitutive relation

$$
D=D_{0} a(T) \omega\left(J_{2}\right) S
$$

where $D$ is the strain-rate tensor, $S$ is a dimensionless deviatoric stress tensor definẽd by

$$
\left.\underset{\sim}{S}=\sigma_{0}-1 \underset{\sim}{(\sigma}+\underset{\sim}{p I}\right), \quad p=-\frac{1}{3} \operatorname{tr} \underset{\sim}{\sigma},
$$

with invariant

$$
\mathrm{J}_{2}=\frac{1}{2} \operatorname{tr} \underset{\sim}{\mathrm{s}^{2}},
$$

and where $D_{0}$ and $\sigma_{0}$ are strain-rate and stress units respectively and $I$ is the unit tensor. The temperaturedependent rate fačtor $a(T)$ becomes a constant defined by its value at the chosen temperature in the isothermal approximation. We adopt the factor

$$
a(T)=\alpha_{1} \exp \left(B_{1} \bar{T}\right)+\alpha_{2} \exp \left(B_{2} \bar{T}\right)
$$

where

$$
T=273.15 K+20 K \bar{T} \text {, }
$$

$\alpha_{1}=0.7242, \beta_{1}=11.9567, \alpha_{2}=0.3438, \beta_{2}=2.9494$, which is a close correlation constructed by Smith and Morland (1981) to the Mellor and Testa (1969) uni- axial compression data at a uniaxial stress of 1.18 $x 10^{6} \mathrm{~N} \mathrm{~m}^{-2}$ over the temperature range $212.15 \mathrm{~K} \leqslant \mathrm{~T} \leqslant$ $273.15 \mathrm{~K}$. The high stress level allows minimum (secondary) creep to be attained, and a common stress for all temperatures gives a direct measure of the temperature influence.

For the stress-dependent function $\omega\left(\mathrm{J}_{2}\right)$ we adopt a polynomial constructed by Smith and Morland (1981) from Glen's (1955) uniaxial compression data at $T=273.13 \mathrm{~K}$, noting that a $(273.13 \mathrm{~K})$ is approximately unity for Equations (11) and (12). Following the $\mathrm{MJ}$ notation

$$
w\left(J_{2}\right)=\frac{3}{2}\left(c_{0}+3 c_{1} J_{2}+9 c_{2} J_{2}{ }^{2}\right)
$$

with

$$
c_{0}=0.2224, c_{1}=0.07111, c_{2}=0.002195
$$

when

$$
\sigma_{0}=10^{5} \mathrm{~N} \mathrm{~m}^{-2}, D_{0}=1 \mathrm{a}^{-1} \text {. }
$$

The polynomial relation exhibits bounded viscosity at zero stress, unlike a power law with exponent $n>1$, and correlates much closer to the same data (Smith and Morland, 1981). Estimates of strain-rates from ice-shelf data (Thomas, 1971, 1973; Holdsworth, 1974 [a]) are considerably lower than the above laboratory rates at corresponding stresses. Since they are available only at a few particular stress levels, and hinge on flow solutions which ignore the significant temperature variation through the depth (Morland and Shoemaker, 1982) we adopt the representation defined by Equations (13) to (15) and scale down the predicted strain-rates by appropriate choice of the constant temperature $T$ in the isothermal theory. The magnitude of $\omega\left(\mathrm{J}_{2}\right)$ for deviatoric stress of order $10^{5} \mathrm{~N} \mathrm{~m}^{-2}$, when $\mathrm{J}_{2}$ is order unity, is order unity.

The $\mathrm{MJ}$ solution is the lead-order approximation of a series solution in a small parameter $\varepsilon$ which is a measure of the surface-slope magnitude. Expressions for the stress and velocities are derived in terms of the unknown profile $h(x)$, which is then shown to satisfy a non-linear second-order ordinary differential equation subject to initial (margin) value and slope. The dimensionless normalized variables and analysis depend on $\varepsilon$ which is determined by individual sheet conditions, but we wish to express the relations and solution in common normalized stress and velocity variables for application to any ice sheet. Accordingly, we start from the lead-order solution expressed in physical variables (Morland and Johnson, 1982), but without eliminating the basal velocity $u_{b}$ by the sliding law. That is

$$
\begin{aligned}
& p=-\sigma_{x x}=-\sigma_{y y}=\rho g(h-y), \quad p_{b}=\rho g(h-f), \\
& \sigma_{x y}=-\rho g h^{\prime}(h-y), \quad \tau_{b}=-\zeta \rho g h^{\prime}(h-f), \\
& u=\zeta u_{b}-\frac{a_{0} D_{0}}{\rho g h^{\prime}}\left\{\bar{g}_{1}\left(\frac{{ }^{\tau} b}{\sigma_{0}}\right)-\bar{g}_{1}\left(\frac{\left|\sigma_{x y}\right|}{\sigma_{0}}\right)\right\}
\end{aligned}
$$

where

$$
\zeta=-\operatorname{sgn}\left(h^{\prime}\right), \quad \bar{g}_{1}(t)=\frac{3}{2} c_{0} t^{2}+\frac{9}{4} c_{1} t^{4}+\frac{9}{2} c_{2} t^{6} .
$$

Note that $\tau_{b}$ denotes $\left|\sigma_{x y}\right|$ and $u_{b}$ denotes $|u|$ on the bed, equivalent to tangential components in the lead-order approximation for small bed slope, and $u$ and $\sigma_{x y}$ on $y=f$ are positive (negative) when $h^{\prime}$ is negative (positive). The profile equation is

$\zeta \frac{d}{d x}\left\{(h-f) u_{b}+a D_{0}(h-f)^{2} \bar{\Omega}\left(\frac{\tau b}{\sigma_{0}}\right)\right\}=q-b$ 
where

$$
\bar{\Omega}(t)=c_{0} t+\frac{9}{5} c_{1} t^{3}+\frac{27}{7} c_{2} t^{5},
$$

subject to the margin conditions

margin: $h-f=0, \zeta\left(h^{\prime}-f^{\prime}\right)\left(-\zeta h^{\prime}\right)^{m}=\left(\frac{\lambda_{0}}{\rho g}\right)^{m}\left(q_{0}-b_{0}\right)_{(20)}$

where

$$
\lambda \simeq \lambda_{0}(h-f), q \simeq q_{0}, b \simeq b_{0} \text { as } h-f \rightarrow 0 .
$$

The $\bar{g}_{1}, \bar{\Omega}$ definitions are more convenient than those of $g$, ss in $M J$ which contain the rate factor $a(T)$. Both $\bar{g}_{1}(t)$ and $\bar{\Omega}(t)$ are order unity when $t$ is order unity, corresponding to deviatoric stress of order $10^{5} \mathrm{~N} \mathrm{~m}^{-2}$.

Now an order of magnitude for the basal shear stress $\tau_{b}$ is the stress unit $\sigma_{0}, 10^{5} \mathrm{~N} \mathrm{~m}^{-2}$, while the magnitude of the basal pressure $\mathrm{pb}$ is greater by a factor $\varepsilon^{-1}$, where $\varepsilon$ is a surface-slope magnitude. Similarly, the normal velocity $v$ has magnitude $q_{m}$, while the longitudinal velocity is greater by a factor $\varepsilon^{-1}$, which follows directly from the mass balance $(\mathrm{MJ})$. We introduce common normalized variables in terms of a fixed slope magnitude

$$
\varepsilon_{0}=0.005 \text {, }
$$

and depth and semi-span related by

$$
h_{0}=\varepsilon_{0} l_{0},
$$

so that $h_{0}$ is determined directly $\iota_{0}$ is specified. Thus

$$
\begin{aligned}
& \left(\sigma_{x y}, \tau_{b}\right)=\sigma_{0}\left(\bar{\sigma}_{x y}, \bar{\tau}_{b}\right), \quad\left(p, p_{b}\right)=\sigma_{0} \varepsilon_{0}{ }^{-1}\left(\bar{p}, \bar{p}_{b}\right) \\
& (v, q, b)=q_{m}(\bar{v}, Q, B), \quad\left(u, u_{b}\right)=q_{m} \varepsilon_{0}-1\left(\bar{u}, \bar{u}_{b}\right),(24) \\
& x=\ell_{0} X, y=h_{0} Y, h(x)=h_{0} H(X), f(x)=h_{0} F(X),
\end{aligned}
$$

and the dimensionless pressure $\bar{p}$ has a unit $p_{0}=$ $\sigma_{0} \varepsilon_{0}^{-1},=200 \times 10^{5} \mathrm{~N} \mathrm{~m}^{-2}$ with the values given in Equations (15) and (22). Choosing an accumulation and normal velocity magnitude

$$
q_{m}=1 \mathrm{~m} \mathrm{a}^{-1} \text {, }
$$

the dimensionless longitudinal velocity $\bar{u}$ has a unit $200 \mathrm{~m} \mathrm{a}^{-1}$.

In these dimensionless variables

$$
\bar{p}_{b}=k(H-F), \quad \bar{\tau}_{b}=-\zeta k H^{\prime}(H-F)
$$

where

$$
k=\frac{\rho g h_{0^{\varepsilon} 0}}{\sigma_{0}}
$$

depends on the value of $h_{0}$ given by Equation (23), that is, on the prescribed semi-span $\iota_{0}$. The profile equation becomes

$$
\zeta \frac{d}{d x}\left\{(H-F) \bar{u}_{b}+a_{0} q_{m}^{-1} h_{0} \varepsilon_{0}(H-F)^{2} s s\left(\bar{\tau}_{b}\right)\right\}=Q-B,
$$

with margin conditions

margin: $H-F=0, \zeta\left(H^{\prime}-F^{\prime}\right)\left(-\zeta H^{\prime}\right)^{m}=\left(\frac{\lambda_{0}}{\rho g \varepsilon_{0}}\right)^{m} \frac{q_{m}\left(Q_{0}-B_{0}\right)}{\varepsilon_{0}}$,

again depending on $h_{0}$. We express the basal sliding Equation (6) in the form

$$
\bar{\tau}_{b}=\bar{\lambda}\left(\bar{p}_{b}\right) \bar{u}_{b} 1 / m=\bar{p}_{b} \bar{\mu}\left(\bar{p}_{b}\right) \bar{u}_{b} 1 / m \text {, }
$$

where the required linear dependence of $\lambda\left(\mathrm{p}_{\mathrm{b}}\right)$ as $\mathrm{pb}_{\mathrm{b}} \rightarrow 0$

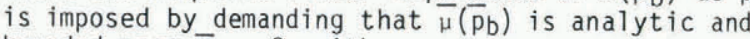
bounded near $\bar{p}_{b}=0$, with

$$
\bar{\mu}_{0}=\bar{\mu}(0)=\frac{\lambda_{0}}{\rho g \varepsilon_{0}}\left(\frac{q_{m}}{\varepsilon_{0}}\right)^{1 / m},
$$

so the coefficient of $\left(Q_{0}-B_{0}\right)$ in the second margin condition (29) is simply $\bar{\mu}_{0} m$.

The MJ solution is obtained by applying a given sliding law (30) to eliminate $\bar{\mu}_{b}$, and solving the consequent second-order non-linear ordinary differential equation (28), subject to initial conditions (29), for the profile $H(X)$. Here we apply Equation (28) to a given profile $H(X)$ with associated surface accumulation/ablation_and basal drainage $Q-B$ to evaluate $\bar{u}_{b}(X)$. With $\bar{p}_{b}(X), \bar{\tau}_{b}(X)$ given by Equations (26) we can, in principle, determine one function $\bar{\lambda}\left(\bar{p}_{b}\right)$ in a sliding relation $(30)$.

\section{GREENLAND ICE SHEET PROFILE (EGIG)}

In order to determine the basal (slip) velocity $\bar{u}_{b}$ from Equation (28) we need to know the surface profile $H(X)$, the bed profile $F(X)$ and the net accumulation/ablation distribution $Q(H)$. We assume henceforth that there is zero drainage at the bed, $B=0$ in Equation (28), since actual values are expected to be less than $0.01 \mathrm{~m} \mathrm{a}^{-1}$ (Boulton, 1983). The physical data for the surface and bed profile is taken from Hofmann (1974), with a corrected "near margin" profile from Holtzscherer and Bauer ([1956]). These data, along with a 7-degree Chebyshev polynomial approximation, appears in Figure $2 a$. The bed form for the EGIG profile is a series of undulations about sea-level, $h=0$ (see e.g. Boulton, 1983). We have investigated both this form and a flat bed at sea-level, obtaining similar global results. Detailed results based on the flat bed assumption are now presented. The accumulation/ablation data (Hofmann, 1974; personal communication from L.D. Williams in 1982) is shown in Figure 2b along with the corresponding 7-degree Chebyshev polynomial approximation.

We choose $\ell$ to be the actual distance between the divide and the margin which are then represented by end points $(0,1)$ in the dimensionless co-ordinate $x$. Here

$$
\ell_{0}=420 \mathrm{~km}, h_{0}=2.1 \mathrm{~km} \text {. }
$$

The accumulation data give

$$
\int_{0} Q d X=0.009 \text {, }
$$

instead of zero required by the steady-state comparison, but this value is extremely small in comparison with both the maximum normalized ablation value 3.75 and the maximum normalized accumulation value 0.52 . A small adjustment to the data is therefore required to obtain a steady-state pattern; a convenient form is to replace $Q(H)$ by $Q_{A}(H)$ where

$$
Q_{A}(H)=Q(H)-\frac{\int_{0}^{1} Q d X}{\int_{0}^{1} H d X} H,
$$

which can be interpreted as a small basal drainage component linearly dependent on altitude in Equation (28). If a function $\bar{Q}(X)$ is prescribed, then Equation (28) is directly integrable and an alternative adjustment 

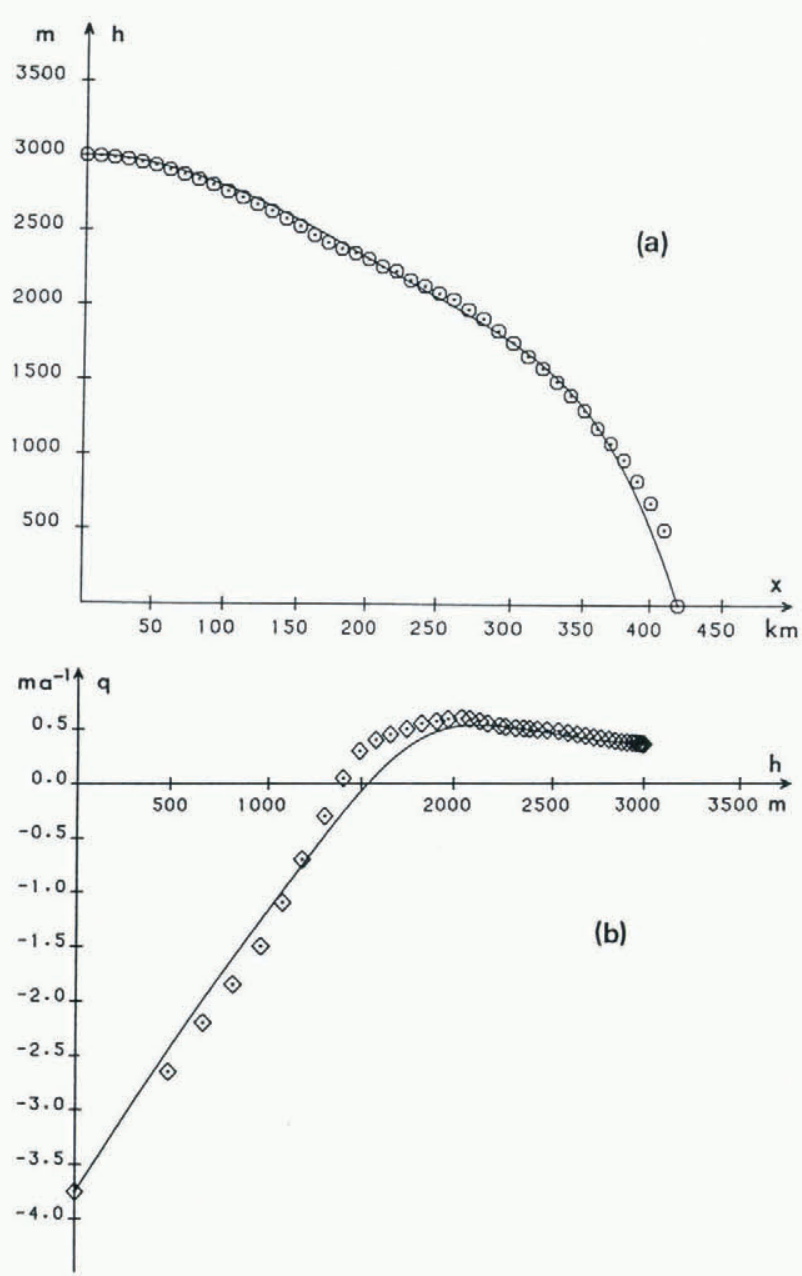

Fig. 2. (a) Greentand profile.

(b) Accumulation/ablation distribution. Continuous curves show Chebyshev polynomial approximations to the data points.

$$
\bar{Q}_{A}(X)=\bar{Q}(X)-\int_{0}^{1} \bar{Q} d X
$$

may be used. Both forms (34) and (35) were used in the numerical calculations and the results were indistinguishable. The results given in this section are based on the adjustment (34).

Using the polynomial representations of $H(X)$ and $Q_{A}(X)$, or $\bar{Q}_{A}(X)$, the differential equation (28) gives the dimensionless basal velocity $\bar{u}_{b}(X)$ displayed in Figure 3 , along with the dimensionless pressure $\bar{p}_{b}$ and dimensionless shear traction $\tau$ given by Equation (26). Also shown is the normalized surface slope $\bar{\tau}_{b} / \bar{p}_{b}$. The three velocity curves in Figure 3 correspond to three different uniform temperatures $T=$ $-30^{\circ} \mathrm{C},-26^{\circ} \mathrm{C},-23^{\circ} \mathrm{C}$, using the temperature-dependent rate factor $\mathrm{a}(\mathrm{T})$ given by Equations (11) and (12); $\mathrm{a}\left(-23^{\circ} \mathrm{C}\right) \approx 10^{-2}, \mathrm{a}\left(-30^{\circ} \mathrm{C}\right) \approx 4 \times 10^{-3}$. These are estimates of mean temperature in the bulk of the inner ice mass (Boulton, 1983). The basal velocities in this example increase monotonically with distance from the divide, reaching a value equivalent to approximately $130 \mathrm{~m} \mathrm{a}^{-1}$ at the margin. Discrepancies from actual values are expected on account of the assumption of a flat bed, and such discrepancies are more noticeable near the margin. The lower the ice temperature the less is the internal deformation, which, for a fixed glacier surface profile and accumulation/ablation distribution, must produce a_compensating increase in the predicted basal velocity $\bar{u}_{b}$. However, the influence of temperature in the isothermal approximation on the

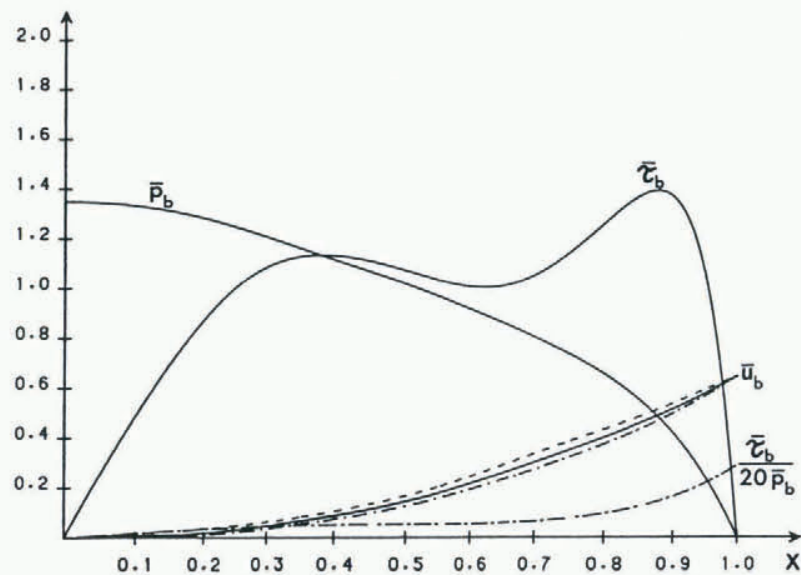

Fig. 3. Distributions of normalized basal pressure $\bar{p}_{b}$, shear traction $\bar{\tau}_{b}$, tangential velocity $\bar{u}_{b}$ and surface slope determined by $\overline{\tau_{b}} / \overline{p_{b}}$ (Greenland profile). The three $\bar{u}_{b}$ curves correspond to $T=-30^{\circ} \mathrm{C}(---),-26^{\circ} \mathrm{C}$ $(-),-23^{\circ} \mathrm{C}(\ldots)$. The units of $\overline{\mathrm{p}}_{b}, \overline{\tau_{b}}, \overline{u_{b}}$ are respectively $200 \times 10^{5} \mathrm{~N} \mathrm{~m}^{-2}, 10^{5} \mathrm{~N} \mathrm{~m}^{-2}, 200 \mathrm{~m} \mathrm{a}^{-1}$.

predicted basal velocity is seen to be negligible in this example. Temperature variation with depth and longitudinal distance may have a more significant effect. Note, though, that in this isothermal approximation, the basal velocity required as a boundary condition for the global flow is not negligible over a major part of the bed, and could not be described by a non-slip condition on the smooth apparent bed.

We now adopt the minimum temperature $\mathrm{T}=-30^{\circ} \mathrm{C}$ of the above set, which represents a natural bound of

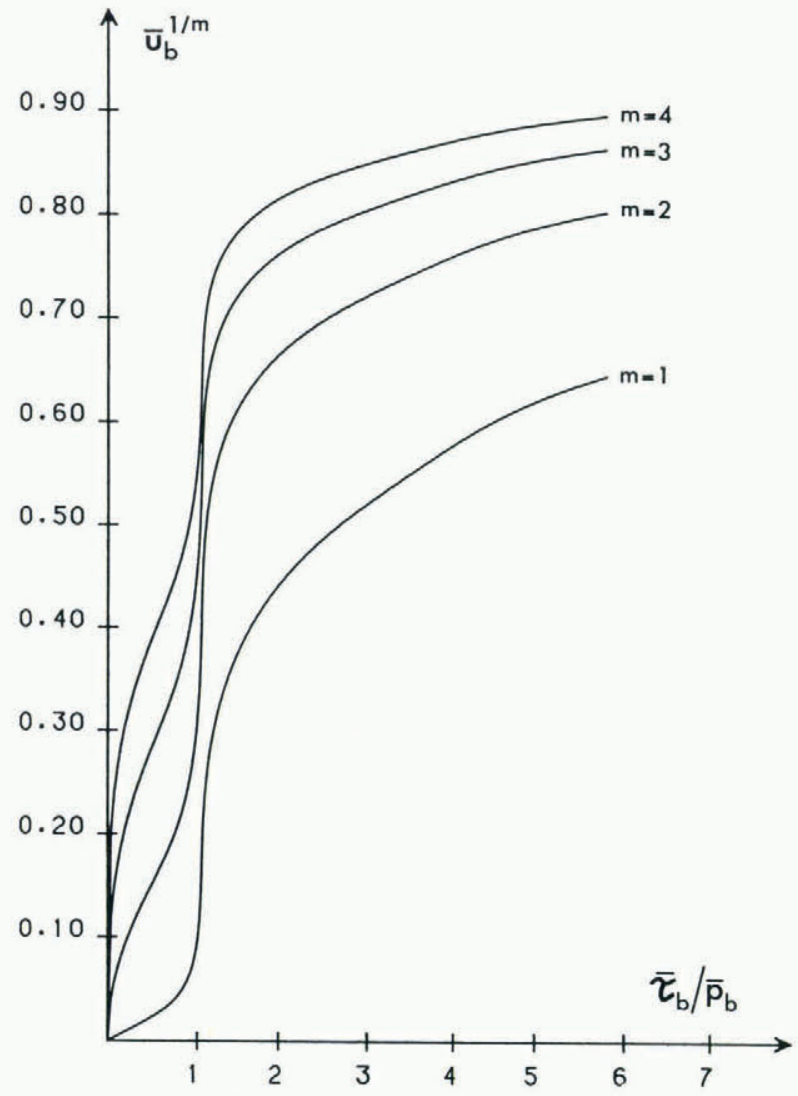

Fig. 4. Variation of $\bar{u}_{b} 1 / m$ with surface slope $\bar{\tau}_{b} / \bar{p}_{b}$ for different values of $m$ (Greenland profile). 


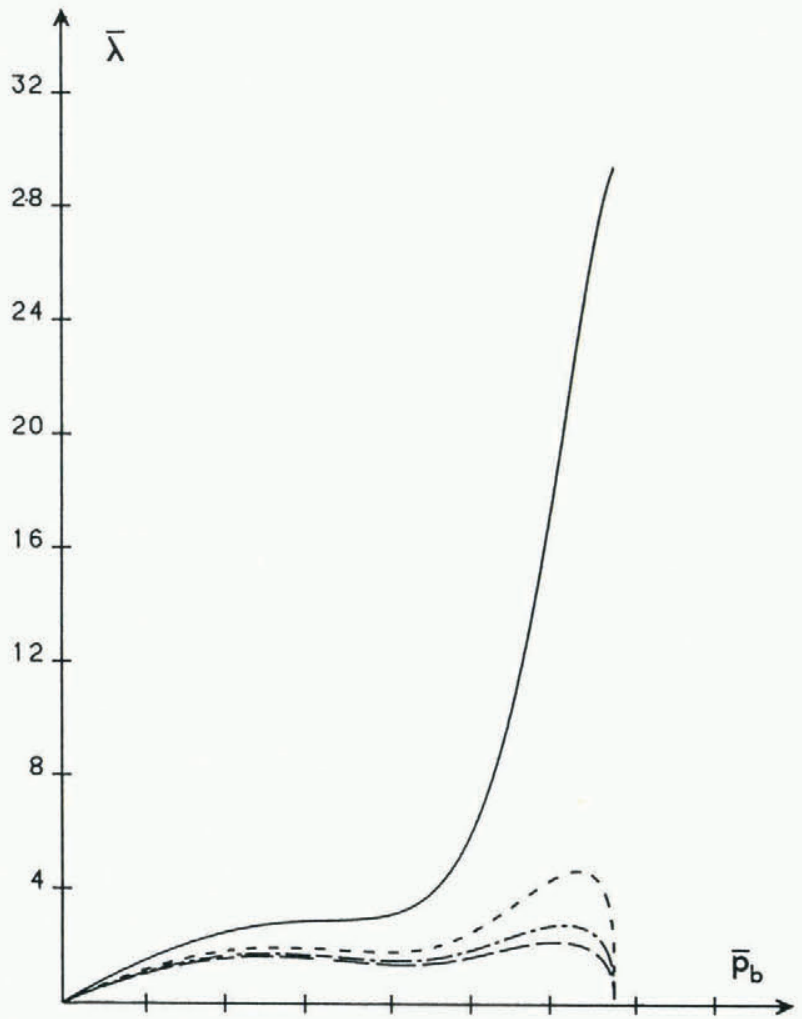

$\begin{array}{lllllllll}0.2 & 0.4 & 0.6 & 0.8 & 1.0 & 1.2 & 1.4 & 1.6\end{array}$

Fig. 5. Sliding coefficient $\bar{\lambda}\left(\bar{p}_{b}\right)=\bar{\tau}_{b} / \bar{u}_{b} 1 / m$ for $m=1$ (ㄱ), $m=2(-.--), m=3(\ldots)$, and $m=4(\ldots)$ (Greenland profile).

mean temperature, to produce the scaled-down strainrates expected in natural ice flow as compared to laboratory creep tests (see earlier discussion on page 133). First we investigate the changes in the function $\lambda\left(p_{b}\right)$ when different values of $m$ are chosen in Equation (30). Figure 4 shows $u_{0} 1 / \mathrm{m}$ versus dimensionless slope $\tau \mathrm{b} / \mathrm{pb}_{\mathrm{b}}$ while Figure 5 shows the function $\bar{\lambda}\left(\bar{p}_{b}\right)=\bar{\tau}_{b} / \bar{u}_{b} 1 / m$ versus $\bar{p}_{b}$ for $m=1,2,3,4$. In both figures the results for $m=2,3,4$ are not strongly dissimilar whereas the results for $m=1$ have distinct features. In Figure 4 it is the behaviour of $\bar{u}_{b} 1 / m$ as $\bar{\tau}_{b} / \bar{p}_{b} \rightarrow 0$, and in Figure 5 it

is the behaviour of $\bar{\tau}_{b} / \bar{u}_{b} 1 / m$ as $\bar{p}_{b}$ approaches its maximum value, both limits occurring at the ice divide. Both figures reflect the limit behaviour at the divide of $\bar{\tau}_{b} / \bar{u}_{b}$ approaching a non-zero finite value

and $\bar{\tau}_{b} / \bar{u}_{b} 1 / m(m>1)$ approaching zero as $\bar{\tau}_{b}$ and $\bar{u} b$ approach zero. The function $\bar{\mu}(\bar{p} b)$ versus $\bar{p} b$ is shown for different values of $\mathrm{m}$ in Figure 6 . It is evident that $\bar{\mu}\left(\bar{p}_{\mathrm{b}}\right)$ is very closely linear, and with the same gradient, for each value of $m$ including $m=1$, until the basal pressure $\bar{p}_{b}$ reaches half its maximum value 1.3 which is attained at the divide. Thus $\bar{\lambda}\left(\bar{p}_{b}\right)$ is accurately represented by a quadratic over this range.

We now focus attention on the case $m=1$, which guarantees a unique surface slope at the margin when ablation occurs there (Morland and Johnson, 1982). For convenient application of a sliding relation such as the second of Equations (30), we require an explicit representation of the function $\mu\left(\bar{p}_{b}\right)$ over the entire range of $\bar{p} b$. A linear form of $\bar{\mu}(\mathrm{pb})$ is assumed for $0 \leqslant \bar{p}_{b} \leqslant 0.7$, while for $0.7 \leqslant \bar{p}_{b} \leqslant 1.3$ a polynomial representation is used which satisfies continuity of $\bar{\mu}, \bar{\mu}^{\prime}$, and $\bar{\mu}^{\prime \prime}$ at $\bar{p}_{b}=0.7$. Correlation by least squares is applied for increasing degree of

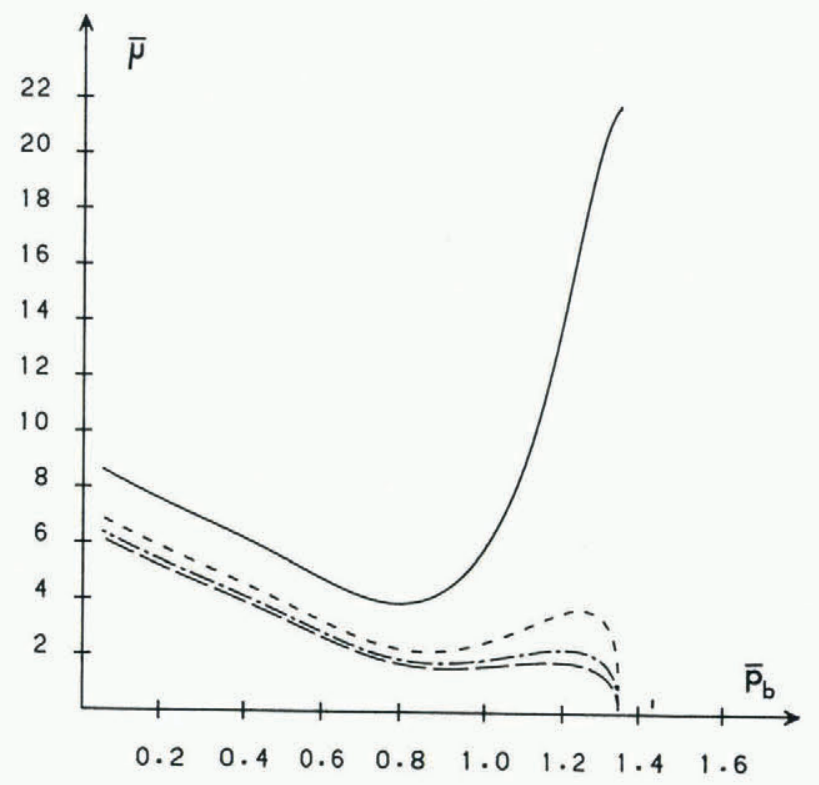

Fig. 6. Reduced coefficient $\bar{\mu}\left(\bar{p}_{b}\right)=\bar{\lambda}\left(\bar{p}_{b}\right) / \overline{p_{b}}$ for $m=1$ (Greeniand profile). $m=3(-.$.$) , and m=4(--)$

polynomial until the resulting function is in good agreement with data, and not distinguishable in the graphical form on the scale of Figure 6 . The result is

$$
\begin{aligned}
\bar{\mu}\left(\overline{\mathrm{p}}_{b}\right) & =9.000-6.657 \overline{\mathrm{p}}_{b}, \quad 0 \leqslant \overline{\mathrm{p}}_{b} \leqslant 0.7, \\
\bar{\mu}\left(\overline{\mathrm{p}}_{b}\right) & =\sum_{r=0} \mu_{r} \overline{\mathrm{p}}_{b}^{r}, \quad 0.7 \leqslant \overline{\mathrm{p}}_{b} \leqslant 1.3, \\
\mu_{0} & =-53.596, \mu_{1}=253.643, \\
\mu_{2} & =-324.134, \mu_{3}=26.753, \\
\mu_{4} & =176.028, \mu_{5}=-72.761 .
\end{aligned}
$$

However, the continuation of this polynomial representation starts to decrease for $\bar{p}_{b}>1.49$. Ice-sheet profiles generated with this sliding relation for which the pressure significantly exceeds this value so that $\bar{\mu}$ returns to its low-pressure values would be physically unsatisfactory. Hence, beyond a pressure $\bar{p}_{m}$ the polynomial form is replaced by a linear extension

$\bar{\mu}\left(\bar{p}_{b}\right)=19.73+54.43\left(\bar{p}_{b}-\bar{p}_{m}\right), \quad \bar{p}_{b} \geqslant \bar{p}_{m}=1.3$,

which satisfies continuity of $\bar{\mu}$ and $\bar{\mu}^{\prime}$ at $\bar{p}_{b}=\bar{p}_{m}$. This latter transition value $\bar{p}_{m}$ is arbitrary but it is chosen near the point of inflexion of the polynomial given by the second of Equations (36), i.e. the value of $\vec{p}$ at which the slope $\bar{\mu}^{\prime}\left(\bar{p}_{b}\right)$ starts to decrease.

The accuracy of the sliding-relation construction (36) can be verified by solving the ordinary differential equation (28) for the EGIG profile $H(X)$ with the given accumulation/ablation distribution shown in Figure $2 b$, with the adjustment (34). A graphical comparison with the original profile (Fig. 2a) shows no distinction. This applies to both Equations (36) and (36) amended by (37) since $\bar{p}_{b}$ does not significantly exceed the transition pressure $\bar{p}_{m}$.

\section{NORTH-WEST DEVON ISLAND ICE CAP PROFILE}

The procedure outlined in the previous section is now repeated for the much smaller north-west profile of the Devon Island ice cap. The surface profile data 
are extracted from Hyndman (1965), which also contains estimates of the bed profile determined by gravity measurements for various cross-sections of the ice cap. Once again calculations are made for both a polynomial representation of the bed based on the available data, and on a simplified version ( $F$ varying linearly with $\mathrm{H}$ ) which reflects similar global results. The results of the simplified version are presented.

The accumulation/ablation data for the north-west profile are taken from Müll er (1977, p. 147-54). A weighted mean of these data, which represent measurements for the years 1960 to 1975 inclusive, is determined in order to achieve an accumulation/ablation pattern which is as nearly as possible in steady state with the assumed profile. Although the margin of the ice cap is approximately $600 \mathrm{~m}$ above sea-level over the island, the accumulation/ablation data shown in Figure $7 \mathrm{~b}$ is for altitudes ranging from the maximum value of $1800 \mathrm{~m}$ at the divide down to zero altitude. The lower-altitude data ( $h<600 \mathrm{~m}$ ) represent measurements on one of the outlet glaciers at the extreme north-west of the ice cap, an estimate of which must be included in the analysis in order to approximate a steady-state system. In Figure 7a the surface profile data for the ice cap and glacier are shown, along with the corresponding 11-degree Chebyshev polynomial representation and the simplified version of the bed profile $(F=7 \mathrm{H} / 9)$ which reproduces measured depths near the summit (Paterson and Clarke, 1978). The span from ice cap divide to the glacier margin gives

$$
l_{0}=43 \mathrm{~km}, h_{0}=0.215 \mathrm{~m} \text {. }
$$

A small adjustment of the form of Equation (34) is necessary in order to obtain a steady-state pattern,
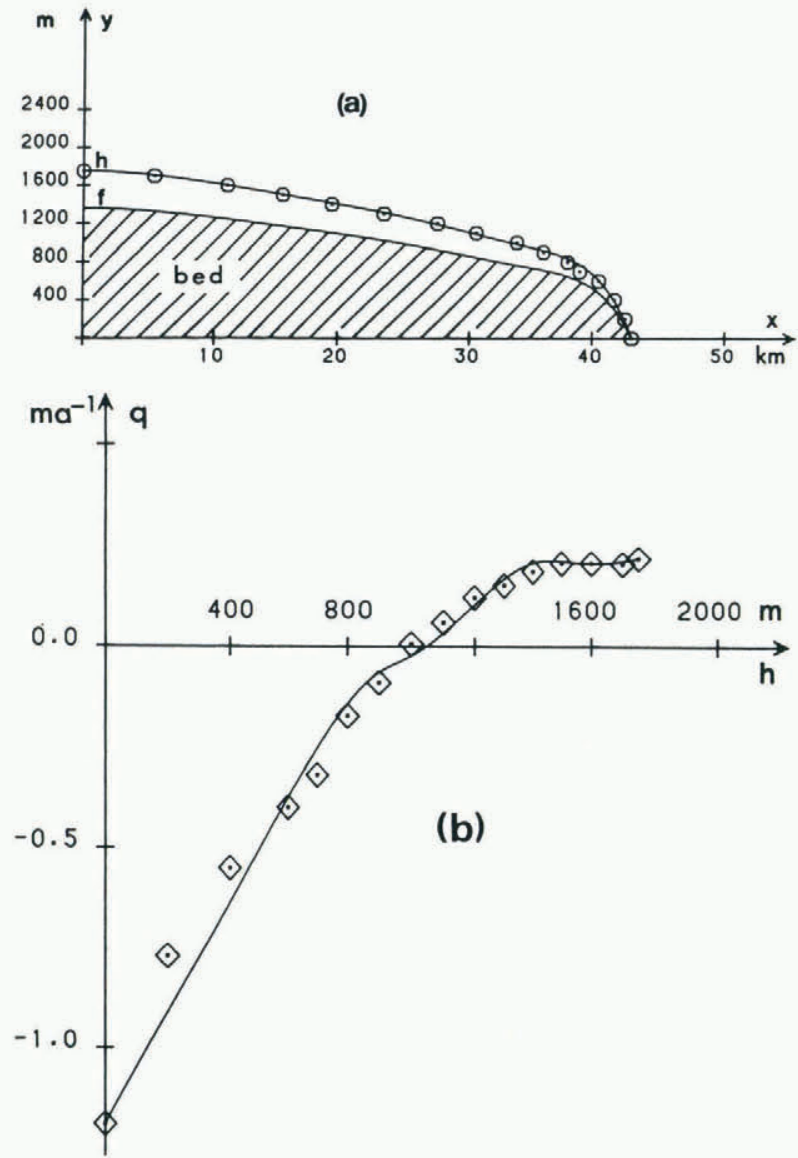

Fig. ?. (a) Devon Island profile.

(b) Accumulation/ablation distribution. Con tinuous curves show Chebyshev polynomial approximations to the data points. the value of the integral (33) here being 0.070 (as opposed to 0.009 for Greenland). Polynomial representations for $h(x)$ and $f(x)$ in Figure $7 a$ and $q(h)$ in Figure 7b, suitably normalized, are used in Equation (28) to determine $u_{b}(X)$. The distribution of velocity $u_{b}$, which now increases only to $13 \mathrm{~m} \mathrm{a}^{-1}$ at the margin, basal pressure $\bar{p}_{b}$ and basal shear traction $\bar{\tau} b$ are shown in Figure 8 , which al so shows the variation of the surface slope $\tau_{b} / \bar{p}_{b}$ with $X$. The calculations

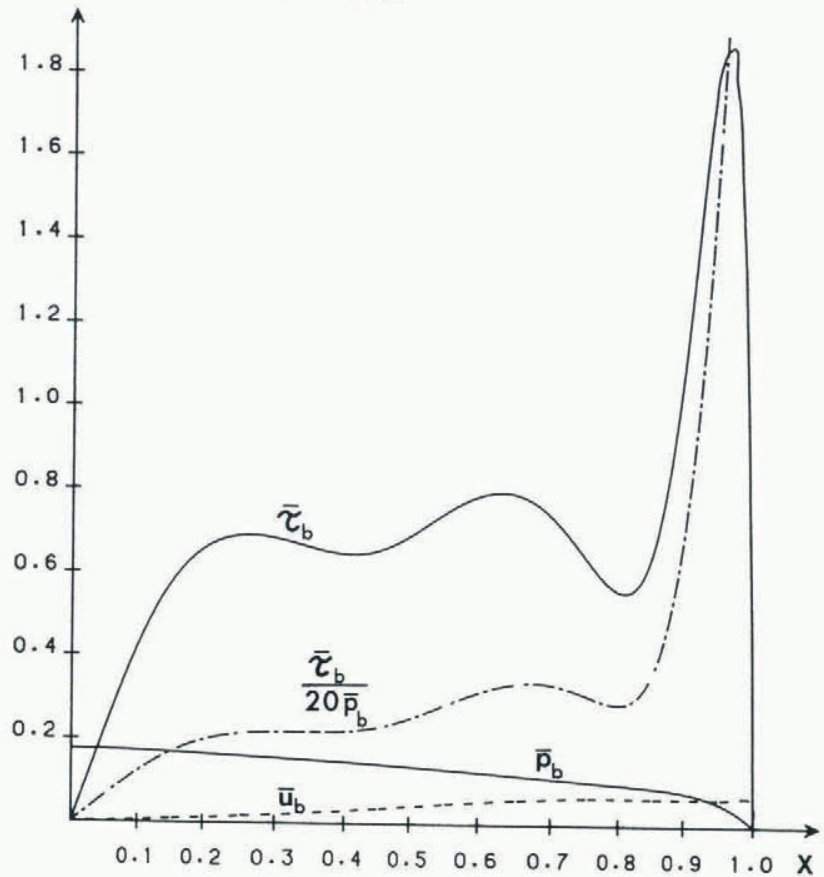

Fig. 8. Distributions of normalized basal pressure $\bar{p}$ shear traction $\tau_{b}$, tangential velocity $u_{b}$ and surface slope determined by $\bar{\tau}_{b} / \overline{p_{b}}$ (Devon Island profile). The $\bar{u}_{b}$ curve corresponds to $T=-30^{\circ} \mathrm{C}(---)$. The units of $\bar{p}_{b}, \bar{\tau}_{b}, \bar{u}_{b}$ are respectively $200 \times 10^{5} \mathrm{~N} \mathrm{~m}^{-2}$, $10^{5} \mathrm{~N} \mathrm{~m}^{-2}, 200 \mathrm{~m} \mathrm{a}^{-1}$.

are again performed for the assumed uniform temperature $\mathrm{T}=-30^{\circ} \mathrm{C}$.

Figure 9 shows the behaviour of $\bar{\lambda}\left(\bar{p}_{b}\right)$ versus $\bar{p}_{b}$ for $m=1,2,3,4$. Once again it is apparent that the case $m=1$ is distinct from the cases $m=2,3,4$ in the limiting behaviour of $\bar{\tau}_{b} / \bar{u}_{b} 1 / m$ as both $\bar{\tau}_{b}$ and

$\bar{u}_{b}$ approach zero at the divide. Figure 10 shows $\bar{\mu}\left(p_{b}\right)$

versus $\bar{p}_{b}$ for $m=1,2,3,4$. We note the similarity in shape with the corresponding curves in Figure 6 , with each again having closely linear sections, but with a different gradient. The vast difference in the range of $\mu\left(\bar{p}_{b}\right)$ for the Greenland (Fig. 6) and Devon Island (Fig. 10) profiles is due mainly to the different scales of the basal pressure, $\bar{p}_{b} \leqslant 1.3$ and $\bar{p}_{b} \leqslant 0.17$ respectively, with the Greenland ice roughly eight times as thick as the Devon ice at corresponding values of distance $X$. An approximate smooth representation of $\bar{\mu}\left(\mathrm{p}_{\mathrm{b}}\right)$ for the $\mathrm{m}=1$ curve in Figure 10 is given by

$$
\begin{aligned}
& \bar{\mu}\left(\overline{\mathrm{p}}_{b}\right)=1000-10000 \overline{\mathrm{p}}_{b}, \quad 0 \leqslant \overline{\mathrm{p}}_{b} \leqslant 0.08, \\
& \bar{\mu}\left(\overline{\mathrm{p}}_{b}\right)=\sum_{r=0}^{3} \mu_{r} \overline{\mathrm{p}}_{b}^{r}, \quad 0.08 \leqslant \overline{\mathrm{p}}_{b} \leqslant 0.15, \\
& \mu_{0}=1424, \quad \mu_{1}=-17346, \\
& \mu_{2}=-15306, \quad \mu_{3}=510204, \\
& \bar{\mu}\left(\overline{\mathrm{p}}_{b}\right)=200+12500\left(\overline{\mathrm{p}}_{b}-0.15\right), \quad \overline{\mathrm{p}}_{b} \geqslant 0.15 .
\end{aligned}
$$




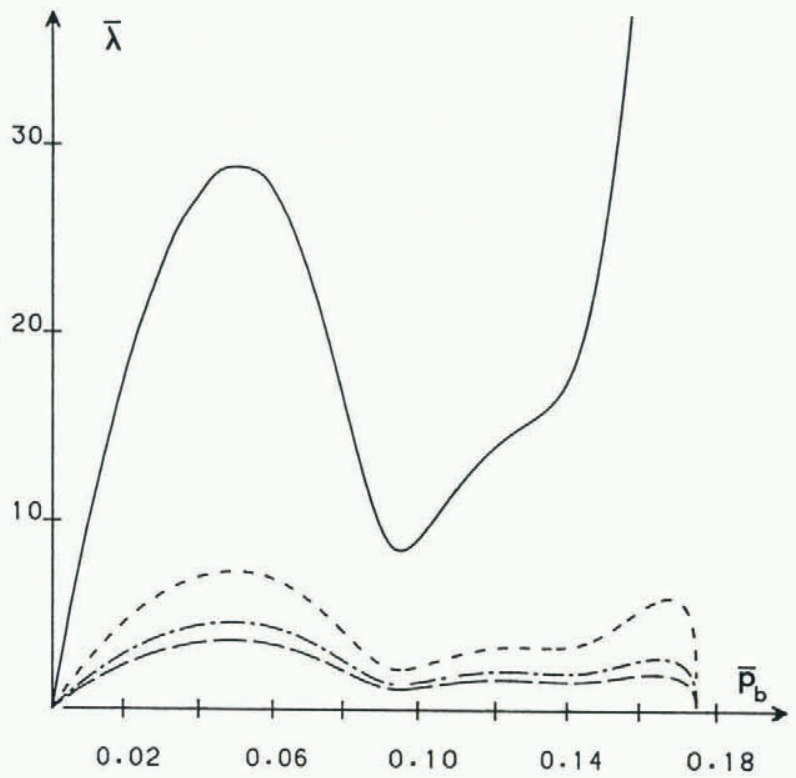

Fig. 9. Sliding coefficient $\bar{\lambda}\left(\bar{p}_{b}\right)=\bar{\tau}_{b} / \bar{u}_{b} 1 / m$ for $m=1(\vec{b}), m=2(---), m=3(-.-$.$) , and m=4$

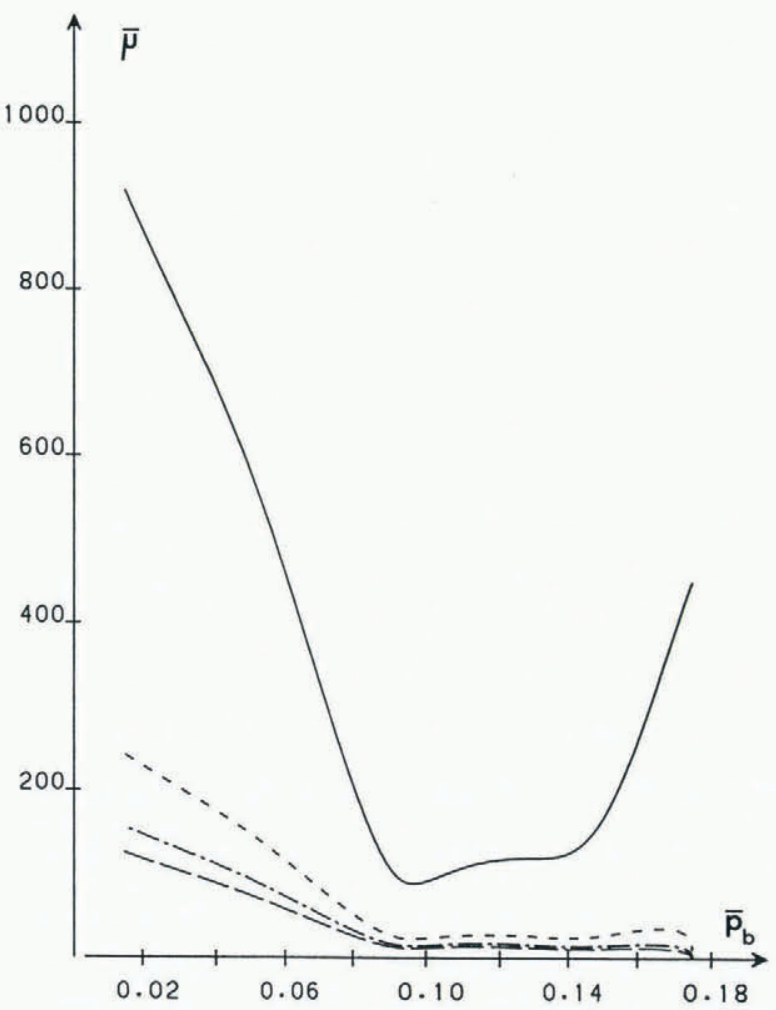

Fig. 10. Reduced coefficient $\bar{\mu}\left(\bar{p}_{b}\right)=\bar{\lambda}\left(\bar{p}_{b}\right) / \bar{p}_{b}$ for $m=1$ (-), $m=2(---), m=3(-.$.$) , and$ $m=4(---)$ (Devon Island profile).

\section{DISCUSSION OF RESULTS}

The steady-state isothermal solution of Morland and Johnson $(1980,1982)$, with different normalization, has been used to determine the basal tangential veloQ city $\bar{u}_{b}$ on a smooth bed contour defining the lower boundary for the global flow. Calculations were made using the surface profile data and accumulation/ ablation data from two very different examples of present-day ice masses, namely the Greenland ice sheet and the Devon Island ice cap. Normalized distributions of the basal pressure $\bar{p}_{b}$, the basal tangential traction $\bar{\tau}_{b}$ and the basal tangential velocity $\bar{u}_{b}$ were determined, and used to find a "friction" parameter $\bar{\lambda}\left(\bar{p}_{\mathrm{b}}\right)$ in an assumed sliding relation of the form of Equation (30) for $m=1,2,3$, and 4 .

It is found for each case that the behaviour of $\bar{\lambda}\left(\overline{\mathrm{p}}_{\mathrm{b}}\right)$ for $\mathrm{m}=2,3$, and 4 is similar but that the $m=1$ results are distinct. This phenomenon stems from the limiting value of $\bar{\tau}_{b} /{ }_{u} / / m$ as both $\bar{\tau}_{b}$ and $\bar{u}_{b}$ approach zero at the divide. For $m=1$, the limit is finite and non-zero, while for $m>1$, the limit is zero. These differences are evident in Figures 4, 5, and 9.

In general, $\bar{\mu}\left(\bar{p}_{b}\right)=\bar{\lambda}\left(\bar{p}_{b}\right) / \bar{p}_{b}$ initially decreases from a finite positive value as $p_{b}$ increases from zero then starts to increase from a mid-range value $\bar{p}_{t}$ of $\bar{p}_{b}$ (see Figs 6 and 10). The main differences between the two examples are

(i) for the Greenland profile $\bar{\lambda}\left(\bar{p}_{b}\right)$ is a monotonic function of $\bar{p} b$, while for the Devon Island ice cap it is not;

(ii) the much smaller range of the Devon Island ice cap basal pressure leads to dramatically larger values of $\bar{\mu}\left(\overline{p_{b}}\right)$.

Such wide differences in magnitude of the function $\bar{\mu}$, and hence $\lambda$ in Equation (6), correspond to wide differences in the calculated basal sliding velocity at given basal shear stress. Bed structure and thermal conditions will influence the gross friction represented by the sliding law, but more significantly, bed mobility could significantly reduce the actual siding velocity. Whereas it is the absolute basal ice velocity which appears in the differential equation (28), it is strictly the relative slip velocity which should enter the sliding relations (4), (6), and (7). Compatibility of the predicted Greenland and Devon basal velocity magnitudes, which approach $130 \mathrm{~m} \mathrm{a}^{-1}$ and $13 \mathrm{~m} \mathrm{a}^{-1}$ at the respective margins, in the common range of overburden pressure could require, though, a significant Greenland bed movement to account for such a large fraction of the calculated basal velocity.

Significant temperature profiles and strong creep dependence on temperature through $a(T)$ will influence the basal velocity calculation, and basal temperature could affect the sliding "friction" or influence bed mobility. Given an empirically deduced temperature field, it is possible to generalize the analysis to incorporate the rate factor $\mathrm{a}[\mathrm{T}(\mathrm{x}, \mathrm{y})]$, and we are now investigating such temperature effects on the basal velocity.

In principle, given ice-sheet data could be correlated to other forms of sliding relations: for example, the form of the first of Equations (4) with $\lambda\left(p_{b}\right)$ prescribed and $\beta\left(u_{b}\right)$ determined. More specifically, if we choose Equation (7) which satisfies the required asymptotic behaviour (5) as $\mathrm{p}_{\mathrm{b}} \rightarrow 0$, then $\beta\left(u_{b}\right)=\tau b / p b$ determined by the Greenland data is represented in the normalized variables $\bar{u}_{b}, \bar{p}_{b}, \bar{\tau}_{b}$ by the curve for $m=1$ in Figure 4 . Note, however, the large gradient of the corresponding $\bar{u}_{b}=\bar{\beta}^{-1}\left(\bar{\tau}_{b}, \bar{p}_{b}\right)$ when $\tau \mathrm{b} / \mathrm{p} b$ is near unity, which is associated with the rapid change of the sliding velocity $\bar{u}_{b}$ while the surface slope changes little. That is, the sliding velocity is very sensitive to small changes of surface slope, and it would be difficult to represent the function $\beta^{-1}$ accurately.

Unfortunately, data from a small set of ice sheets cannot determine a function of two variables such as $\tau_{b}\left(p_{b}, u_{b}\right)$, so we must start with restricted forms such as Equation (6), or Equation (6) extended to include a temperature-dependent factor. It is clear that there is no universal sliding law, and choice of a basal sliding condition will depend on the particular application. Until thermal and bed-structure effects are established, a range of sliding conditions should 
be considered to estimate their influence on solutions. Such a parameter study has been included in an investigation of equilibrium profiles in various environments by Boulton and others (1984).

\section{ACKNOWLEDGEMENT}

This work was supported by a United Kingdom Natural Environment Research Council Grant GR3/4114: Relationship between glaciers and climate during the last glacial period in north-west Europe.

\section{REFERENCES}

Boulton, G.S. 1972. The role of thermal régime in glacial sedimentation. (In Price, R.J., and Sugden, D.E., comp. Polar geomorphology. London, Institute of British Geographers, p. 1-19. (Institute of British Geographers. Special Publication No. 4.))

Boulton, G.S. 1979. Processes of glacier erosion on different substrata. Journal of Glaciology, Vol. 23, No. 89 , p. $15-38$.

Boulton, G.S, 1983. Debris and isotopic sequences in basal layers of polar ice sheets. (In Robin, G. de Q., ed. The climatic record in polar ice sheets. Cambridge, etc., Cambridge University Press, p. 8389.)

Boulton, G.S., and others. 1979. Direct measurement of stress at the base of a glacier, by G.S. Boulton, E.M. Morris, A.A. Armstrong, and A. Thomas. Journal of Glaciology, Vol. 22, No. 86, p. 3-24.

Boulton, G.S., and others. 1984. The reconstruction of former ice sheets and their mass balance characteristics using a non-linearly viscous flow model, by G.S. Boulton, G.D. Smith, and L.W. Morland. Journal of Glaciology, Vol. 30, №. 105, p. 140-52.

Colbeck, S.C., and Evans, R.J. 1973. A flow law for temperate glacier ice. Journal of Glaciology, Vol. 12, No. 64, p. 71-86.

Fowler, A.C. 1979. A mathematical approach to the theory of glacier sliding. Journal of Glaciology, Vol. 23, No. 89, p. 131-41.

Fowler, A.C. 1981. A theoretical treatment of the sliding of glaciers in the absence of cavitation. Philosophical Transactions of the Royal Society of London, Ser. A, Vol. 298, No. 1445, p. 637-85.

Glen, J.W. 1955. The creep of polycrystalline ice. Proceedings of the Royal Society of London, Ser. A, Vol. 228, No. 1175 , p. 519-38.

Goldthwait, R.P. 1960. Study of ice cliff in Nunatarssuaq, Greenland. U.S. Snow, Ice and Permafrost Research Establishment. Technical Report 39.

Hofmann, W. 1974. Die Internationale Glaziologische Grönland-Expedition (EGIG). 2. Die geodätische Lagemessung. Eisbewegung 1959-1967 in den EGIG-Profilen. Zeitschrift für Gletscherkunde und Glazialgeologie, Bd. 10, p. 217-24.

Holdsworth, G. 1974[a]. Erebus Glacier tongue, McMurdo Sound, Antarctica. Journal of Glaciology, Vol. 13, No. 67 , p. 27-35.

Holdsworth, G. 1974[b]. Meserve Glacier, Wright Valley, Antarctica: part I. Basal processes. Ohio State University. Institute of Polar Studies. Report No. 37.

Holtzscherer, J.-J., and Bauer, A. [1956.] Contribution à la connaissance de $i$ 'indlandsis du Groen1 and. Union Géodésique et Géophysique Internationale. Association Internationale d'Hydrologie Scientifique. Assemblée générale de Rome, 1954. Tom. 4, p. 244-96. (Publication No. 39 de 1 'Association Internationale d'Hydrologie.)
Hyndman, R.D. 1965. Gravity measurements on the Devon Island ice cap and an adjoining glacier. Journal of Glaciology, Vol . 5, No. 40, p. 489-96.

Johnson, I.R. 198i. The steady profile of an axisymmetric ice sheet. Journal of Glaciology, Vol. 27, No. 95, p. 25-37

Kamb, W.B., and LaChapelle, E.R. 1964. Direct observation of the mechanism of glacier sliding over bedrock. Journal of Glaciology, Vol. 5, No. 38, p. 15972.

Lliboutry, L.A. 1968. General theory of subglacial cavitation and sliding of temperate glaciers. Journal of Glaciology, Vol. 7, No. 49, p. 21-58.

Lliboutry, L.A. 1979. Local friction laws for glaciers: a critical review and new openings. Journal of Glaciology, Vol. 23, No. 89, p. 67-95.

Mellor, M., and Testa, R. 1969. Effect of temperature on the creep of ice. Journal of Glaciology, Vol. 8, No. 52 , p. 131-45.

Morland, L.W. 1976. Glacier sliding down an inclined wavy bed. Journal of Glaciology, Vol. 17, No. 77, p. 447-62.

Mori and, L.W., and Johnson, I.R. 1980. Steady motion of ice sheets. Journal of Glaciology, Vol. 25, No. 92, p. 229-46.

Morl and, L.W., and Johnson, I.R. 1982. Effects of bed inclination and topography on steady isothermal ice sheets. Journal of Glaciology, Vol. 28, No. 98, p. 71-90.

Morland, L.W., and Shoemaker, E.M. 1982. Ice shelf balances. Cold Regions Science and Technology, Vol. 5 , No. 3 , p. 235-41.

Müller, F. 1977. Fluctuations of glaciers, 1970 1975. (Vol. III.) A contribution to the International Hydrological Programme. Compiled for the Permanent Service on the Fluctuations of Glaciers of the IUGG-FAGS/ICSU. Paris, International Commission on Snow and Ice of the International Association of Hydrological Sciences and UNESCO.

Nye, J.F. 1959. The motion of ice sheets and glaciers. Journal of Glaciology, Vol. 3, No. 26, p. 493-507.

Nye, J.F. 1969. A calculation on the sliding of ice over a wavy surface using a Newtonian viscous approximation. Proceedings of the Royal Society of London, Ser. A, Vol. 311, No. 1506, p. 445-67.

Paterson, W.S.B., and Clark, G.K.C. 1978. Comparison of theoretical and observed temperature profiles in Devon Island ice cap, Canada. Geophysical Journal of the Royal Astronomical Society, Vol. 55, No. 3, p. 615-32.

Peterson, D.N. 1970. Glaciological investigations on the Casement Glacier, southeast Alaska. Ohio State University. Institute of Polar Studies. Report No. 36.

Smith, G.D., and Morland, L.W. 1981. Viscous relations for the steady creep of polycrystalline ice. Cold Regions Science and Technology, Vol. 5, No. 2, p. $141-50$.

Thomas, R.H. 1971. Flow law for Antarctic ice shelves. Nature, Physical Science, Vol. 232, No. 30, p. 85-87.

Thomas, R.H. 1973. The creep of ice shelves: interpretation of observed behaviour. Journal of Glaciology, Vol. 12, No. 64, p. 55-70.

Vivian, R.A. 1980. The nature of the ice-rock interface: the results of investigations on $20000 \mathrm{~m} 2$ of the rock bed of temperate glaciers. Journal of Glaciology, Vol . 25, No. 92, p. 267-77.

Weertman, J. 1957. On the sliding of glaciers. Journal of Glaciology, Vol. 3, No. 21, p. 33-38.

Weertman, J. 1964. The theory of glacier sliding. Journal of Glaciology, Vol. 5, No. 39, p. 287-303.

Weertman, J. 1979. The unsolved general glacier sliding problem. Journal of Glaciology, Vol. 23, No. 89, p. $97-115$. 